\title{
CROTACETIN, A NOVEL SNAKE VENOM C-TYPE LECTIN, IS HOMOLOG OF CONVULXIN
}

\author{
RÁDIS-BAPTISTA G. (1), MORENO F. B. M. B. (1), NOGUEIRA L. L. (1), \\ MARTINS A. M. C. (2), TOYAMA D. O. (3), TOYAMA M. H. (4), AZEVEDO JR W. F.
} (5), CAVADA B. S. (1), YAMANE T. (6)

(1) Department of Biochemistry and Molecular Biology, Federal University of Ceará (UFC), Ceará, Brazil; (2) Department of Clinical and Toxicological Analyses, Federal University of Ceará (UFC), Ceará, Brazil; (3) Department of Biochemistry, State University of Campinas (UNICAMP), São Paulo, Brazil; (4) Department of Chemistry, São Paulo State University (UNESP), São Paulo, Brazil; (5) Department of Physics, Institute of Biosciences, Humanities and Exact Sciences, São Paulo State University (UNESP), São Paulo, Brazil; (6) Molecular Biology Center, Institute of Nuclear Energy and Research (IPEN), São Paulo, Brazil.

ABSTRACT: Snake venom (sv) C-type lectins encompass a group of hemorrhagic toxins, which are able to interfere with hemostasis. They share significant similarity in their primary structures with C-type lectins of other animals, and also present a conserved carbohydrate recognition domain (CRD). A very well studied sv C-type lectin is the heterodimeric toxin, convulxin (CVX), from the venoms of South American rattlesnakes, Crotalus durissus terrificus and $C$. $d$. cascavella. It consists of two subunits, alfa $(\mathrm{CVX} \alpha, 13.9 \mathrm{kDa})$ and beta $(\mathrm{CVX} \beta, 12.6 \mathrm{kDa})$, joined by inter and intra-chain disulfide bounds, and is arranged in a tetrameric $\alpha_{4} \beta_{4}$ conformation. Convulxin is able to activate platelet and induce their aggregation by acting via p62/GPVI collagen receptor. Several cDNA precursors, homolog of CVX subunits, were cloned by PCR homology screening. As determined by computational analysis, one of them, named crotacetin $\beta$ subunit, was predicted as a polypeptide with a tridimensional conformation very similar to other subunits of convulxin-like snake toxins. Crotacetin was purified from $C$. durissus venoms by gel permeation and reverse phase high performance liquid chromatography. The heterodimeric crotacetin is expressed in the venoms of several $C$. durissus subspecies, but it is prevalent in the venom of $C$. durissus cascavella. As inferred from homology modeling, crotacetin induces platelet aggregation but noticeably exhibits antimicrobial activity against Gram-positive and Gram-negative bacteria.

KEY WORDS: Crotalus durisssus venom, snake venom C-type lectin, homology modeling, platelet aggregation, antimicrobial activity.

\section{CORRESPONDENCE TO:}

GANDHI RÁDIS-BAPTISTA, Departamento de Bioquímica e Biologia Molecular, Universidade Federal do Ceará, Campus do Picí, P.O. Box: 6020, 60451-970, Fortaleza, Ceará, Brazil. Phone: +55 854008 9817. Fax: +55 854008 9789. Email: radisbra@ufc.br. 


\section{INTRODUCTION}

Snake venoms are complex mixtures of polypeptides and organics with the ability to paralyze, kill and digest any prey organism. The venom composition is diverse, differing between species (inter-specific venom variations) and individuals (intraspecific venom variations) (28). Hereditary and epigenetic factors (e.g., geographical distribution, diet, snake maturity) contribute to the venom variability $(8,25,43,44$, 47). Based on the victim's symptoms of snakebite, snake venom can basically be classified as neurotoxic or hemorrhagic. Neurotoxins act on ion channels and neural receptors (17). Hemorrhagic toxins interfere with blood stasis and their major classes encompass metalloproteases, phospholipases, disintegrins, and C-type lectins, as reviewed $(3,26)$. C-type lectins are animal proteins of about 130 amino acids long, containing at least a carbohydrate recognition domain (CRD) capable of mediating sugar and calcium binding. The carbohydrate recognition is directly related to some biological activities like cell-cell adhesion, serum glycoprotein turnover, and innate immune responses against potential pathogens (9). Snake venom C-type lectins also contain the conserved CRD and share significant primary structure similarities with the majority of C-type lectins, but most of them neither necessarily bind to carbohydrate molecules nor require calcium ions for their activity $(3,9)$. For instance, convulxin (CVX), a very well studied snake venom C-type lectin, induces $\mathrm{Ca}^{2+}$ dependent platelet aggregation, which is inhibited and reversed by EDTA (49). Convulxin is a heterodimeric toxin from the venoms of South American rattlesnakes, Crotalus durissus terrificus and C. $d$. cascavella $(36,49)$. This protein consists of two subunits, alfa ( $C V X \alpha, 13.9 \mathrm{kDa})$ and beta $(\mathrm{CVX} \beta, 12.6 \mathrm{kDa})$, joined by inter and intrachain disulfide bounds, arranged in a tetrameric $\alpha_{4} \beta_{4}$ conformation $(4,29)$. The $\mathrm{Ca}^{2+}-$ dependent activation of platelets and their aggregation are mediated via p62/GPVI collagen receptor $(35,49)$. Some other snake toxins with similar properties of activating and aggregating platelets are also known. They are bitiscetin, from the venom of Bitis arietans (16); botrocetin, from Bothrops jararaca (12); flavocetin A (13); ophioluxin, a protein from Ophiophagus hannah (10); and mucrocetin, a plateletagglutinin from Trimeresurus mucrosquamatus (20). Recombinant convulxin (rCVX) has been cloned and expressed in Drosophila cells. Purified rCVX from cell culture supernatants binds strongly to human platelet GPVI in western blot assay when whole platelet proteins or recombinant human GPVI are used as targets. Importantly, 
rCVX induces the aggregation of platelets in platelet-rich plasma, indicating that the recombinant CVX subunits can assemble into a functionally competent complex (14). During the procedures for the cloning of convulxin $\alpha$ and $\beta$ subunits, we have isolated several cDNA precursors which are CVX subunit homologs.

In this work, we have characterized one of them, a new member of the snake venom C-type lectin family, named crotacetin (CTC), with predictable platelet aggregation property and unexpected antimicrobial activity.

\section{MATERIALS AND METHODS}

\section{Snake and snake venom}

For the construction of the venom gland cDNA library, a pair of glands was excised from an adult specimen of Crotalus durissus terrificus captured in São Paulo State and provided by the Laboratory of Herpetology, Butantan Institute, São Paulo, Brazil. The snake was milked for venom collection and induction of the maximum level of RNA synthesis in the venom gland (41). The crude venom was vacuum dried and kept at $-20^{\circ} \mathrm{C}$ until protein purification. The venom of Crotalus durissus cascavella was a gift from the Regional Snake Laboratory of Fortaleza (LAROF), Ceará, Brazil. The venom of Crotalus durissus collilineatus was purchased from the Bio-Agents Serpentarium, located in the city of Batatais, São Paulo, Brazil.

\section{Crotalus durissus terrificus venom gland cDNA library construction}

The cDNA library was constructed as described elsewhere (38). Briefly, poly $\left(\mathrm{A}^{+}\right)$ RNAs were purified from a pair of venom glands excised from a single specimen of South American rattlesnake, C. $d$. terrificus (Cdt 9706). The complementary DNAs (cDNAs) were synthesized, selected by size, and cloned into a phagemid vector - a lambda phage derivative ( $\lambda$ Zapll, Strategene). Recombinant phagemids were packed into viable phage particles and used to infect E. coli XL1 Blue MRF' cells (Stratagene, La Jolla, CA). The venom gland cDNA library was titrated, amplified, and stored at $-80^{\circ} \mathrm{C}$, in $7 \% \mathrm{DMSO}$, for posterior utilization.

\section{PCR homology cloning}

Based on nucleotide sequences of subunits $\alpha$ (or $A$ ) and $\beta$ (or B) of convulxin (CVX) from C. durissus terrificus (GenBank accession no. AF541882 and Y16348, 
convulxin subunit alpha; AF541881 and Y16349, convulxin subunit beta), we were able to synthetize (Invitrogen Life Technologies, Brazil) one oligonucleotide forward primer, CVXA/B-FW1 (5'-TCTCTCTGCAGGGAAGGAAG-3'), and two reverse primers, CVXA-RV1A (5'-TCCTTGCTTCTCCAGACTTCA-3') and CVXB-RV2B (5'ACTTCACACAGCCGGATCTT-3'), which correspond to 5'-UTR of CVX subunits $\alpha$ and $\beta$ (forward primer), and to 3'-UTRs of CVX subunit $\alpha$ (reverse primer RV1A) and subunit $\beta$ (reverse primer RV2B), respectively. The gene of one subunit of crotacetin (CTC $\alpha$ subunit) was amplified with the same primer pair used to amplify CVX subunit $\alpha$, in the following way: phage particles $\left(10^{7}-10^{8} \mathrm{pfu}\right)$ of $C$. durissus terrificus venom gland cDNA library, 10 pmoles of each primer, and $25 \mu$ of ExLONGase enzyme mix (Invitrogen Life Technologies, San Diego, CA) were mixed and the polymerase chain reaction (PCR) was performed according to the manufacturer's instructions. The long distance PCR (LD-PCR) products were purified from the gel slice and cloned into pCR2.1-TOPO (Invitrogen Life Technologies, San Diego, CA).

The gene was sequenced with ABI Prism Big Dye Terminator (Perkin Elmer, Foster City, CA) in an automated sequencer (ABI Prism 373 or 377, Perkin Elmer) using synthetic oligonucleotides designed for CVXA/B sequences (this work). The cloned crotacetin mRNA (accession number AF541884) was compared against nucleotide sequences on the GenBank at NCBI (31), using the BLAST algorithm and the Biocomputing software Lasergene (DNAStar, Inc., Madison, WI).

\section{Similarity search and homology modeling}

The amino acid sequence predicted from the respective Crotalus durissus terrificus precursor cDNA was compared against the protein data bank (pdb) (40) using BLASTP, as a tool for protein search and alignment (2). Several sequences, chosen as the best score after alignment, were used to identify conserved residues in homologous sequences. Snake venom C-type lectin sequences from the venoms of Trimeresurus flavoviridis ( $\mathrm{pdb}$ entry code 1C3A, chain B) (13), Trimeresurus mucrosquamatus (1V4L, chain B) (20) and Crotalus durissus terrificus (1UOS, chain $B$ and 1 UMR, chain B) $(4,29)$ were aligned by CLUSTALW (18) using default parameters. 
To build a tridimensional structure of СTC $\beta$ subunit C-type lectin, one thousand models were generated with PARMODEL (48), which parallel the MODELLER (42) software in a Beowulf cluster (16 nodes). The best model was selected according to the modeller objective function and was evaluated by PROCHECK (24), WHATCHECK (19), and 3DANALYSIS (5). The permissible angles of amino acid residues in the spatial structure of CTC $\beta$ subunit were also evaluated by RAMACHANDRAN plot (39).

\section{Crotacetin purification}

Whole venom (35 mg) was dissolved in a 0.2-M ammonium bicarbonate buffer $(\mathrm{pH}$ 8.0) and then clarified by high-speed centrifugation (4500xg for $1 \mathrm{~min}$ ). The supernatant was injected onto a molecular exclusion HPLC column (Superdex 75, 1 x $60 \mathrm{~cm}$, GE Healthcare), previously equilibrated with the same buffer used for solubilization of the whole venom. Chromatographic process was performed with a flow rate of $0.2 \mathrm{ml} / \mathrm{min}$, and monitored at $280 \mathrm{~nm}$. Fractions corresponding to crotacetin were pooled and lyophilized. After this first step of purification, crotacetin was re-purified by reverse phase HPLC. Approximately $1 \mathrm{mg}$ of the purified protein was dissolved in the buffer A (TFA $0.1 \%$ in aqueous solution), used for equilibration of the analytical $\mu$-Bondapack C18 column $(0.39 \times 30 \mathrm{~cm})$. The elution of highly purified crotacetin was carried out using a linear and discontinuous buffer B gradient (66\% of Acetonitrile in buffer A). The chromatographic run was conducted at constant flow rate of $1.0 \mathrm{ml} / \mathrm{min}$ and monitored at $214 \mathrm{~nm}$.

\section{Reduction, S-carboxymethylation and determination of $\mathrm{N}$-terminal sequence}

Two milligrams of purified crotacetin were dissolved in $200 \mu \mathrm{l}$ of a 6.0-M guanidine chloride solution (Merck, Darmstadt, Germany) containing $0.4 \mathrm{M}$ Tris- $\mathrm{HCl}$ and $2 \mathrm{mM}$ EDTA ( $\mathrm{pH}$ 8.15). Nitrogen was blown over the top of the protein solution for $15 \mathrm{~min}$, followed by molecular reduction with $200 \mu \mathrm{l}$ of $6.0 \mathrm{M}$ dithiotreitol (DTT) and further carboxymethylation with ${ }^{14} \mathrm{C}$-iodoacetic acid and cold iodoacetic acid. Nitrogen was again blown over the surface of the solution and the reaction tube was sealed. This solution was incubated in the dark at $37^{\circ} \mathrm{C}$ for 1 hour and desalted using a Sephadex G25 column $(0.7 \times 12 \mathrm{~cm})$ with $1.0 \mathrm{M}$ acetic acid buffer. The eluted RC-Crotacetin was then applied on the reverse phase HPLC $\mu$-Bondapack C-18 column $(0.39 \times 30$ 
$\mathrm{cm}$ ), previously equilibrated with buffer A (TFA $0.1 \%$ in aqueous solution). The subunits of crotacetin were eluted with a nonlinear gradient concentration of buffer $B$ (acetonitrile $66 \%$ in buffer A), and the fractions corresponding to each crotacetin subunit were recovered, lyophilized, and stored at $-80^{\circ} \mathrm{C}$. Crotacetin subunits were then sequenced by automatic Edman degradation, using a gas-liquid protein sequencer (Applied Biosystems model Precise). The amino acid phenylthiohydantoin (PTH) derivatives were identified using a PTH-analyzer (Applied Biosystems model 450 micro-gradient).

\section{Platelet aggregation}

Platelet-rich plasma (PRP) was prepared as described by Chudzinski-Tavassi et al. (7), and the evaluation of platelet aggregation was performed with a Chrono-Log Lumi aggregometer (Havertown, PA). PRP samples were incubated at $37^{\circ} \mathrm{C}$ for 2 min with different concentrations of purified crotacetin. Platelet agglutination was monitored by turbidimetry and expressed as an increase of light transmittance. Collagen was used as control of platelet aggregation.

\section{Antimicrobial activity and electron microscopy}

Xanthomonas axonopodis pv passiflorae (Gram-negative) or Clavibacter michiganensis michiganensis cells were harvested from fresh agar plates, and suspended in sterile distilled water $\left(A_{650 \mathrm{~nm}}=0.3 / \mathrm{cc} 10^{3} \mathrm{CFU} / \mathrm{ml}\right)$. Aliquots of bacterial suspension were diluted to $10^{-5} \mathrm{CFU} / \mathrm{ml}$ and incubated with crotacetin $(150 \mu \mathrm{g} / \mathrm{ml})$ during 20 minutes at $37^{\circ} \mathrm{C}$. Then, the capacity of survival was assayed on nutrient (Difco) plates $(n=5)$. In both antibacterial assays, morphological alterations were visualized by electron microscopic, in absence (control) or presence of crotacetin $\left(A_{650 n m}=0.3 / \mathrm{cc} 10^{3} \mathrm{CFU} / \mathrm{ml}\right)$. For this purpose, bacterial samples were fixed with $1 \%$ osmium tetraoxide (Agar Scientific Ltd) for $2 \mathrm{~h}$ at $25^{\circ} \mathrm{C}$. Sections were washed three times, dehydrated in increasing concentrations of ethanol and propylene oxide, and embedded in Epon resin (Agar Scientific). Polymerization was performed at $60^{\circ} \mathrm{C}$ for $48 \mathrm{~h}$, and ultrathin sections were prepared with a Sorvall MT2 ultramicrotome. The sections were placed on 5\% collodion-coated 100-mesh grids, and stained with 4\% uranyl acetate (Agar Scientific) for $15 \mathrm{~min}$, followed by $2.6 \%$ lead citrate (Agar Scientific) for $15 \mathrm{~min}$. Samples were observed with a Hitachi 1100 transmission electron microscope (Hitachi Scientific Instruments, Japan), operating at $100 \mathrm{kV}$. 


\section{RESULTS}

\section{PCR homology cloning of crotacetin $\beta$ subunit}

The gene coding for crotacetin $\beta$ subunit, СTC $\beta$, (GenBank accession number AF541884) was isolated from Crotalus durissus terrificus venom gland cDNA library by PCR-homology screening with specific primers for the 5'-UTR and 3'-UTR of both convulxin subunits $\alpha(\mathrm{CVX} \alpha)$ and $\beta(\mathrm{CVX} \beta)$, as described in the section materials and methods.

The cloned CTC $\beta$ gene is 513 base pairs (bp) long with a 5'-untranslated region (5'UTR) strictly conserved in all convulxin-like and anti-thrombin-like precursors isolated so far (Figure 1). In CTC $\beta$ gene, the ATG start codon is located 28 bp downstream, and the stop codon (TGA) is located 496 bp. A sequence corresponding to the signal peptide lies between the nucleotides 28 and 96 (Figure 1, underlined).

At nucleotide level, the similarity between CTC $\beta$ and $C V X \beta$ is higher than between CTC $\beta$ and CVX $\alpha$ or CTC $\beta$ and anti-thrombin-like subunit (ATLs). In contrast, the similarity of $\mathrm{CVX} \alpha$ and ATLs is proportionally high. The CTC $\beta$ gene precursor predicts a polypeptide of 148 residues of amino acids, 23 corresponding to the leader sequence, and a molecular mass of $14.3 \mathrm{kDa}$.

\section{Sequence alignment and tridimensional modeling}

Comparison of predicted amino acid sequence of CTC $\beta$ gene against protein data bank reveals high similarity between CTC $\beta$ and C-type lectin subunits from the venom of Trimeresurus flavoviridis ( $\mathrm{pdb}$ entry code 1C3A, chain B), Trimeresurus mucrosquamatus (1V4L, chain B) and Crotalus durissus terrificus (1UOS, chain B and 1UMR, chain B) (Figure 2A). The similarity between CTC $\beta$ and these other snake venom aggregating toxins is around 50\%. If conserved substitutions are considered, the similarity exceeds $70 \%$. In primary structure of CTC $\beta$, the eight residues of cysteine are located in the same position of all aligned sequences. These positions include six residues that are involved in the intra-chain disulfide bridges, and two other "extra" cysteines in the carboxi- (Cys3) and amino- (Cys77) terminals. The model of СTC $\beta$, generated by computer programs, shows an overall topology of five $\beta$-strands and two $\alpha$-helices forming a globular structure with a lateral loop similar to the other convulxin-like C-type lectins (Figure 2B). The lateral loop 
contributes to the formation of heterodimers that are stabilized by the "extra" cysteine residue.

Ramachandran diagram of CTC $\beta$ model indicates that psi $(\psi)$ and phi $(\phi)$ angles of the majority of amino acid residues are located in a thermodynamically favorable region (Figure $2 \mathrm{C}$ ).

Isolation, reduction and determination of $\mathrm{N}$-terminal sequence of crotacetin from C. durissus

By exclusion chromatography, crotacetin appear as a minor fraction peak in the venom of at least three Crotalus durissus subspecies, namely, Crotalus durissus cascavella, Crotalus durissus terrificus and Crotalus durissus collilineatus (Figure $3 A)$. In the venom of Crotalus durissus cascavella, the amount of crotacetin is significantly abundant (it represents around $0.8 \%$ of the proteins in the crude venom). Thus, crotacetin was isolated and characterized from this venom. Purified crotacetin from Crotalus durissus cascavella shows an apparent molecular mass of $70 \mathrm{kDa}$ by gel permeation chromatography, and it appears as two subunits of different sizes by reverse phase HPLC (Figure 3B). Furthermore, by molecular exclusion chromatography, it appears as a high molecular weight protein, indicating the presence of oligomeric forms.

The partial N-terminal amino acid sequence of purified crotacetin ( $\beta$ subunit) corresponds to the one predicted from the gene sequence (Figure $3 \mathrm{C}$ ).

\section{Platelet aggregation assay}

Crotacetin is capable of aggregating human platelet in platelet rich plasma (PRP) in a dose-dependent manner: $22 \%$ at a concentration of $32.8 \mu \mathrm{g} / \mathrm{ml}(47 \mu \mathrm{M}), 36 \%$ at 49.3 $\mu \mathrm{g} / \mathrm{ml}(70 \mu \mathrm{M})$, and $84 \%$ at $65.5 \mu \mathrm{g} / \mathrm{ml}(94 \mu \mathrm{M})$ (Figure 4).

\section{Antimicrobial activity of native crotacetin and isolated $\alpha$ and $\beta$ subunits}

The whole (intact) crotacetin protein decreased the bacterial growth of two plant pathogens: Xanthomonas a. pv. passiflorae, Gram-negative, and Clavibacter $\mathrm{m}$. michiganensis, Gram-positive. The inhibition rates were about $87.8 \%$ and $96.4 \%$, respectively. The isolated chains did not show significant antimicrobial activity (Figures $5 \mathrm{a}$ and $5 \mathrm{~b}$ ) for the species of bacteria tested. In the case of Xanthomonas $a$. pv. passiflorae, crotacetin induced a massive vacuolization of cell cytoplasm and, in some cases, ruptured the cell membrane (Figures $5 \mathrm{c}$ and $5 \mathrm{~d}$ ). 
G. Rádis-Baptista et al. CROTACETIN, A NOVEL SNAKE VENOM C-TYPE LECTIN, IS HOMOLOG OF CONVULXIN. J. Venom. Anim. Toxins incl. Trop. Dis., 2005, 11, 4, p. 565

AF541881_CVX $\beta$ AF541884_CTC $\beta$ CTC subunit $\beta$ AF541882_CVXa AF541883_ATLS

Af541881_CVX $\beta$ Af541884_CTC $\beta$ CTC subunit $\beta$ Af541882_CVX $\alpha$ Af541883_ATLS

Af541881_CVX $\beta$ Af541884_CTC $\beta$ CTC subunit $\beta$ Af541882_CVX $\alpha$ Af541883_ATLS

Af541881_CVX $\beta$ Af541884_CTC $\beta$ CTC subunit $\beta$ Af541882_CVX $\alpha$ Af541883_ATLS

Af541881_CVX $\beta$ Af541884_CTC $\beta$ CTC subunit $\beta$ Af541882_CVX $\alpha$ Af541883_ATLS

Af541881_CVX $\beta$ Af541884_CTC $\beta$ CTC subunit $\beta$ Af541882_CVX $\alpha$ Af541883_ATLS

Af541881_CVX $\beta$ Af541884_CTC $\beta$ CTC subunit $\beta$ Af541882_CVX $\alpha$ Af541883_ATLS

Af541881 CVX $\beta$ Af541884_CTC $\beta$ CTC subunit $\beta$ Af541882_CVXa Af541883_ATLs

Af541881_CVX $\beta$ Af541884_CTC $\beta$ CTC subunit $\beta$ Af541882_CVX $\alpha$ Af541883_ATLS
TCTCTCTGCAGGGAAGGAAGGAAGACCATGGGGCGATTCATCTTCGTGAGCTTCGGCTTG $6 \odot$ TCTCTCTGCAGGGAAGGAAGGAAGGCCATGGGGCGATTGGTGTTCGTGAGCTTCGGCTTG $6 \odot$

$$
\begin{array}{llllllllllll}
M & G & R & L & V & F & V & S & F & G & L
\end{array}
$$

TCTCTCTGCAGGGAAGGAAGGAAGACCATGGGGCGATTCATCTTCGTGAGCTTCGGCTTG 60 TCTCTCTGCAGGGAAGGAAGGAAGACCATGGGGCGATTCATCTTCGTGAGCTTCGGCTTG 60

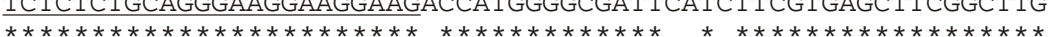

CTGGTCGTGTTCCTCTCCCTGAGTGGAAGTGAAGCTGGTTTCTGTTGTCCCTCCCATTGG 120 CTGGTCGTGTTCCTCTCCCTGACTGGAACTGGAGCTGGTTTCTGTTGTCCCTTGGGTTGG 120 $\begin{array}{llllllllllllllllllll}\mathbf{L} & \mathbf{V} & \mathbf{V} & \mathbf{F} & \mathbf{L} & \mathbf{S} & \mathbf{L} & \mathbf{T} & \mathbf{G} & \mathbf{T} & \mathbf{G} & \mathbf{A} & \mathbf{G} & \mathbf{F} & \mathbf{C} & \mathbf{C} & \mathbf{P} & \mathbf{L} & \mathbf{G} & \mathbf{W}\end{array}$ CTGGTCCTGTTCCTCTCCCTGAGTGGTACTGGAGCTGGTTTACATTGTCCCTCTGATTGG 120 CTGGTCGTGTTCCTCTCCCTGAGTGGTACTGGAGCTGATTTTGATTGTCCCTCTGGTTGG 120 $* * * * * * * * * * * * * * * * * * * * * * * * * * * * * * * * * * * * * * * * * * * \quad * * * *$

TCTTCCTATGATCGGTATTGCTACAAGGTCTTCAAACAAGAGATGACCTGGGCCGATGCA 180 TCTTCCTATGAAGGGCATTGCTACAAGGTCTTCAAACAAGACATGACCTGGGAAGATGCA 180 $\begin{array}{llllllllllllllllllll}\mathbf{S} & \mathbf{S} & \mathbf{Y} & \mathbf{E} & \mathbf{G} & \mathbf{H} & \mathbf{C} & \mathbf{Y} & \mathbf{K} & \mathbf{V} & \mathbf{F} & \mathbf{K} & \mathbf{Q} & \mathbf{D} & \mathbf{M} & \mathbf{T} & \mathbf{W} & \mathbf{E} & \mathbf{D} & \mathbf{A}\end{array}$

TATTACTATGATCAGCATTGCTACCGGATCTTCAATGAAGAGATGAACTGGGAAGATGCA 180 TCCGCCTATGATCAGTATTGCTACAGGGTCATCAAACAACTCAAGACGTGGGAAGATGCA 180

GAGAAATTCTGCACACAACAGCACACAGGCAGCCATCTGGTCTCCTTTCACAGCACTGAA 240 GAGAAATTCTGCACACAACAGCACGAAGGAAGCCATCTGGTCTCCCTTCAGAGCAGTGAA 240

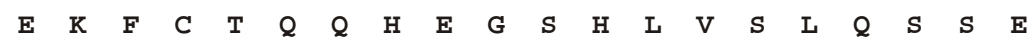

GAGTGGTTCTGCACGAAGCAGGCGAAGGGCGCGCATCTCGTCTCTATCAAAAGCGCCAAA 240 GAGTGGTTCTGCACGAAGCAGGCGAAGGGCGCGCATCTCGTCTCTGTCGAAAGCGCCGGA 240 $* * * * * * * * * * * * * * \quad * * \quad * * * * * * * * * * * * * *$ *

GAAGTAGATTTTGTGGTCAAGATGACC - CACCAAAGTTTGA - -AGTCCACTTT - - -TTTC 294 GAAGTAGATTTTGTGATCTCGATGACCGCACCAATGTT-GA - -AATTGGGTTT - - -AGTC 294

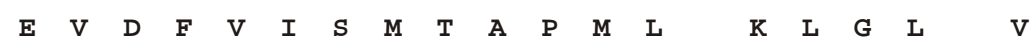

GAAGCAGACTTTGTGGCCTGGATGGTCACTCAGAACATAGAGGAATCCTTTTCCCATGTC 300 GAAGCAGACTTTGTGGCCCAGCTGGTTGCTGAGAACATAAAGCAAAACAAATACTATGTC 300 $* * * * * * * * * * * * * * * \quad * \quad * \quad * * * * \quad * \quad * *$

TGGATTGGAGCGAA - - - CAATATCTGGAATA - -AATGCAACTGGCAGTGGAGCGATGGC 348 TGGATCGGACTGAG - - - - CAATATCTGGAATG - - AATGCACGTTGGAGTGGACCAATGGC 348

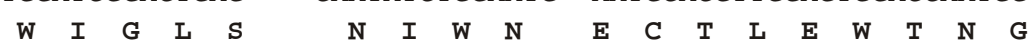

TCGATTGGACTGAGGGTTCAAAACAAAGAAAAGCAATGCAGCACGAAGTGGAGCGATGGC 360 TGGATTGGACTGAGGATTCAAAACAAAGGACAGCAATGCAGCACGAAGTGGAGCGATGGC 360 $* * * * * * * * \quad * * * * * * * * * * * * \quad * * * * * * * * * * * *$

ACCAAGCCTGAGTACGAAGAATGGCATGAAGAATTT - - - - - GAATGTCTCATATCCAG - 401 AACAAGGTCGACTACAAAGCCTGGAGTGCAGAACCT - - - - - - GAGTGTATCGTATCCAA- 401

$$
\begin{array}{lllllllllllllllllllll} 
& \mathbf{N} & \mathbf{K} & \mathbf{V} & \mathbf{D} & \mathbf{Y} & \mathbf{K} & \mathbf{A} & \mathbf{W} & \mathbf{S} & \mathbf{A} & \mathbf{E} & \mathbf{P} & & \mathbf{E} & \mathbf{C} & \mathbf{I} & \mathbf{V} & \mathbf{S} & \mathbf{K}
\end{array}
$$

TCCAGCGTCAGTTATGACAACTTGTTGGATCTATATATTACAAAGTGTAGTCTGCTGAAA 420 TCCAGTGTCAATTATGAGAACCTGCTTAAATCATATTCCAAAAAGTGTTTTGGGCTGAAA 420 $* *$

- - - - GACATTTGATAACCAGTGGTTAAGTGCACCCTGCAGTGATACTTACTCTTTCGTC 456 - - - - GTCAACTGATAAACACTGGTTCAGTAGACCCTGCAGCAAGACTCACAAAGTCGTC 456 $\begin{array}{llllllllllllllllll}S & T & D & K & H & W & F & S & R & P & C & S & K & T & H & K & V & V\end{array}$

AAAGAGACAGGGTTTCGTAAGTGGTTCGTTGCTAGCTGTATAGGAAAGATTCCTTTCGTC 480 AAAGAGACAGAGTTTCTTCAATGGTACAATACTGACTGCGAAGAAAAAAACCTTTTTGTC 480

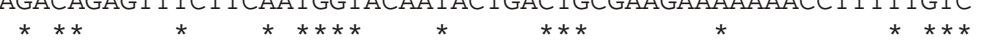

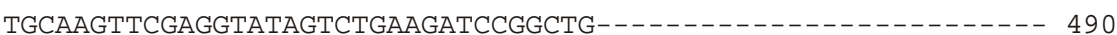
TGCAAGTTCCAGGCATAGTCTGAAGATCCAGCTGTGTGAAGTCTGGAGAAGCAAGGA - - 513 C $K$ F $Q$ Q $A$ *

TGCAAGTTCCCGCCACAGTGTTAAGATCCAGCTTTGTGAAGTCTGGAGAAGCAAGGA - - - 537 TGCAAGTTCCCGCCACAGCGTTAAGATCCGGCTGTGTGAAGT - - - - - - - - - - - - - 522 $* * * * * * * * * *_{*} * * * * * * * * * * * *$

Figure 1: Comparison between nucleotide sequences of crotacetin subunit $\beta$, convulxin subunits $\alpha$ and $\beta$, and anti-thrombin-like subunit precursors. 
All genes were isolated from $C$. $d$. terrificus venom gland cDNA phage library by PCR homology screening. Sequences were aligned using CLUSTALW (26) with default parameters. The Arabic numerals in the left side of each precursor correspond to their GenBank accession numbers (AF541881, convulxin subunit b mRNA; AF541882, convulxin subunit a mRNA; AF541883, anti-thrombin like mRNA; and AF541884, crotacetin subunit b mRNA, all from Crotalus durissus terrificus). Start and stop codons are boxed in gray. Strictly conserved 5'-untraslated sequences (5'UTR), where the primer CVXA/B FW exactly anneals, are underlined. Asterisks represent conserved nucleotides of homologous sequences. Deduced amino acid sequence is presented under the nucleotide sequences in bold capital letters. The signal peptide is underlined.

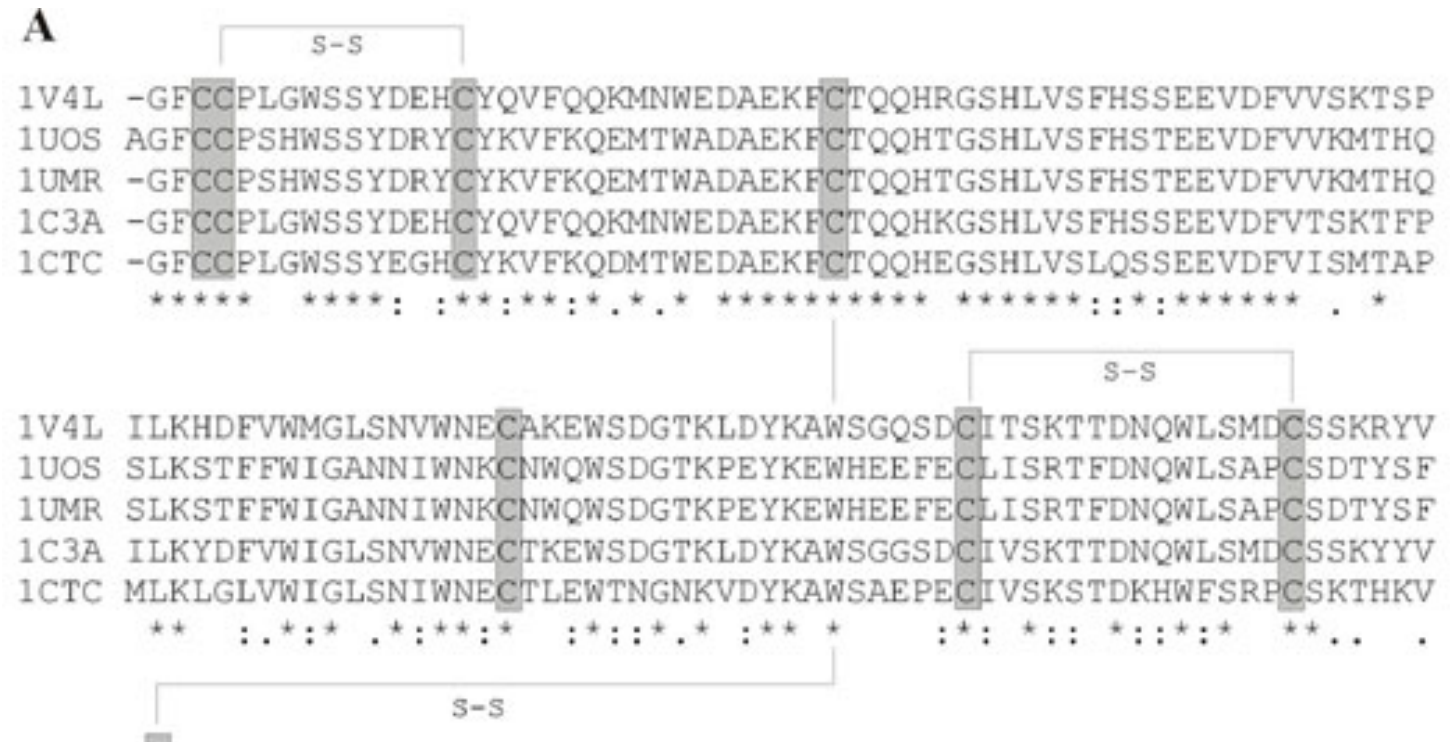

1V4L VCKFQA

IUOS VCKFEA

1 UMR VCKFEA

$1 C 3 A$ VCKFQA

1 CTC VCKFQA $* * * *: *$

B

C
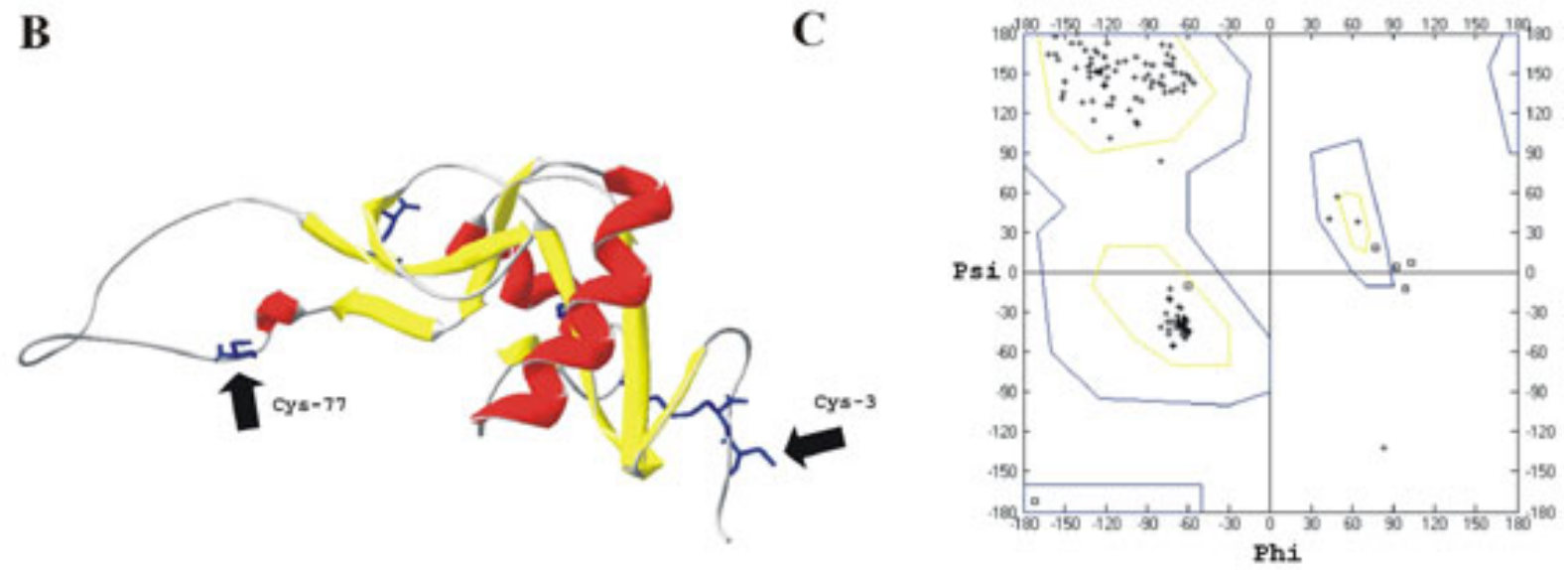

Figure 2: Structural analysis of crotacetin subunit $\beta$.

A - Comparison of deduced amino acid sequence of crotacetin subunit $\beta$, from $C$. $d$. terrificus (this work), with other snake venom C-type lectin subunit sequences from 
protein data bank. The alignment was performed by CLUSTALW. The amino acid sequences are from Trimeresurus flavoviridis (pdb entry 1C3A, chain B), Trimeresurus mucrosquamatus (1V4L, chain B), and Crotalus durissus terrificus (1UOS, chain B and 1 UMR, chain B). Cysteine residues are represented in gray and disulfide bridges by connecting lines.

B - Computer generated model of crotacetin subunit $\beta$.

The 3-D structure was generated with PARMODEL (27). Non-pairing intra-chain and cysteine "extra" residues, in the positions 3 and 77, are indicated by arrows.

C - The Ramachandran plot of CTC $\beta$.

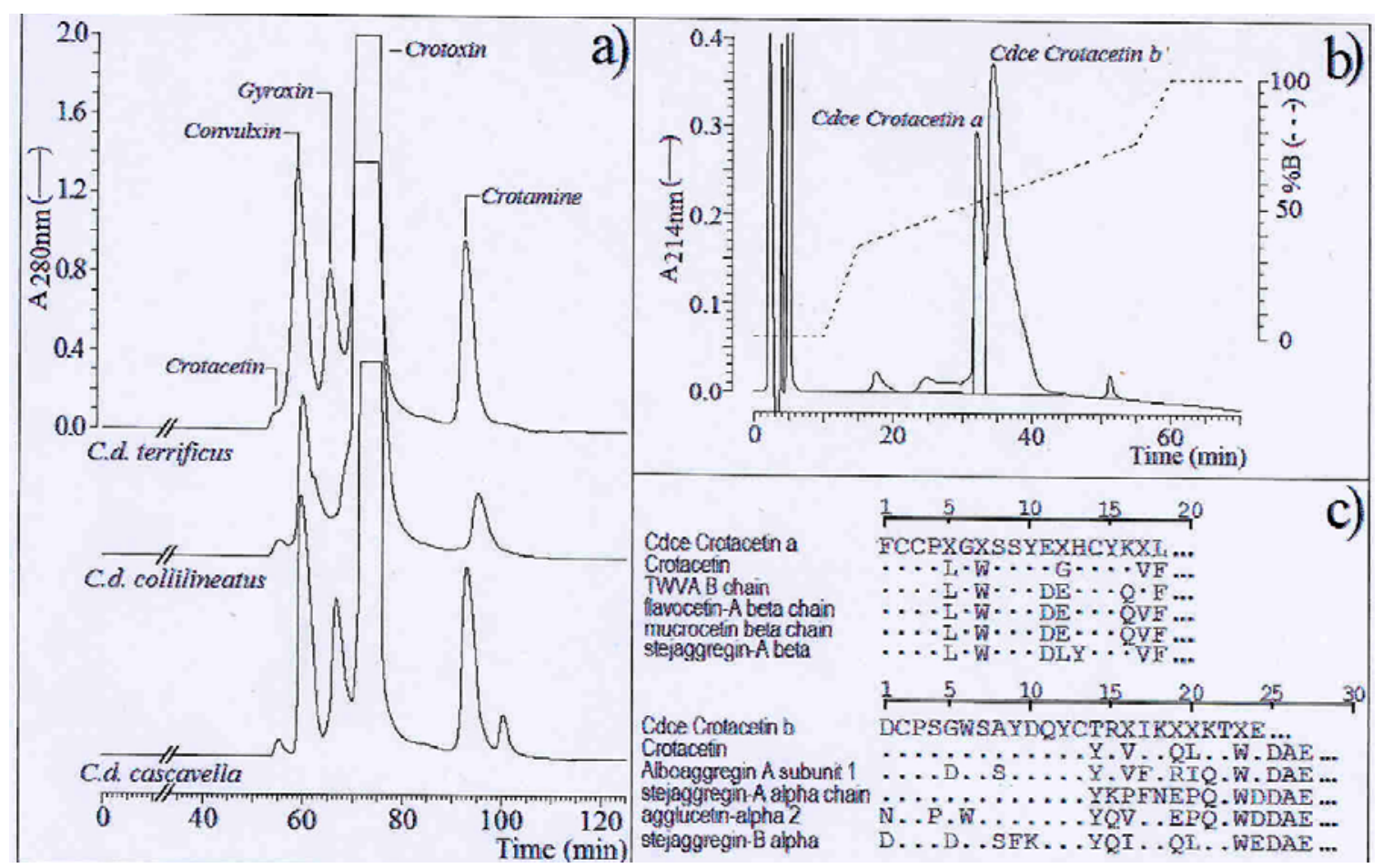

Figure 3: Isolation, reduction and determination of $\mathrm{N}$-terminal sequence of crotacetin from $C$. durissus subspecies.

Crotacetin was purified from the most abundant source, the crude venom of $C$. durissus cascavella, by a combination of gel permeation HPLC (Superdex 75, 1 × 60 $\mathrm{cm}$ ) and sequential reverse phase HPLC, as described in materials and methods.

A - Gel permeation chromatography of the crude venom of three different subspecies of Crotalus durissus (C. d. terrificus, C. d. collilineatus, and C. d. cascavella). The peaks corresponding to crotacetin and other toxins are indicated.

B - Reverse phase HPLC ( $\mu$-Bond pack C-18 column) profile of reduced crotacetin, where the peaks of subunits $\alpha$ and $\beta$ are separated.

C - N-terminal sequences of crotacetin subunits $\alpha$ and $\beta$, and comparison with the predicted amino acid sequence (this work) and with other snake venom C-type lectins. 


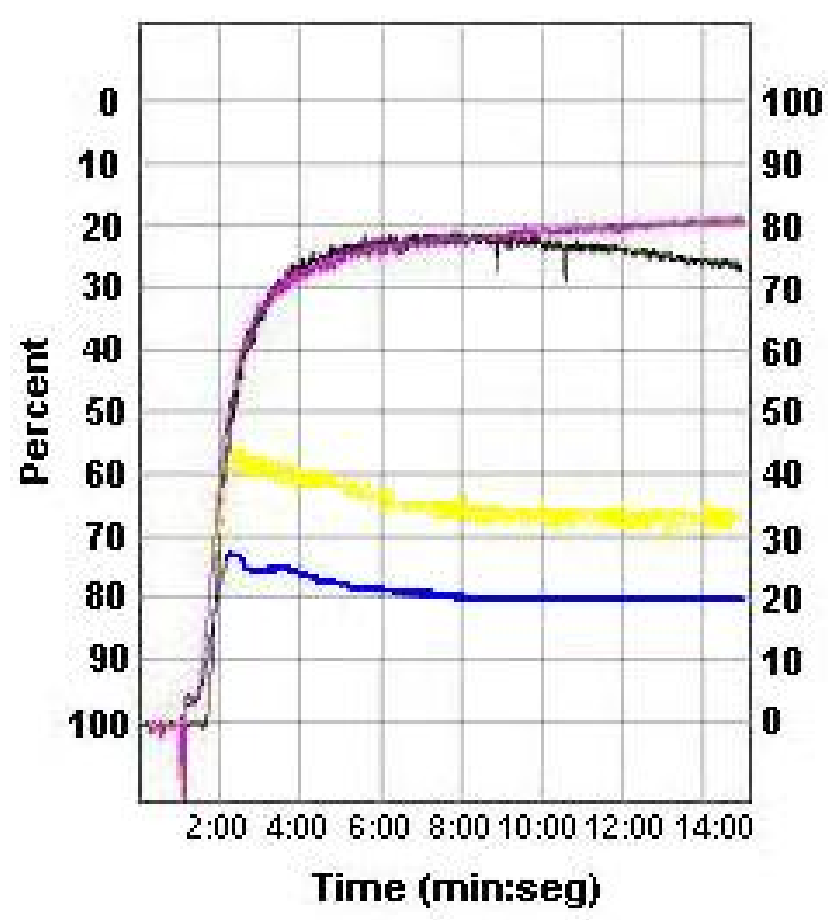

Figure 4: Platelet aggregation.

Assay of platelet aggregation was carried out with human platelet rich plasma (PRP) and increasing quantity of pure crotacetin $(32.8 \mu \mathrm{g} / \mathrm{ml}$, blue curve; $49.3 \mu \mathrm{g} / \mathrm{ml}$, yellow; $65.5 \mu \mathrm{g} / \mathrm{ml}$, magenta). Collagen was used as control (black curve). Aggregation response was monitored by turbidimetry and represented by percent of light transmittance ( $\mathrm{Y}$-axis) versus time, in minutes ( $\mathrm{X}$-axis). 


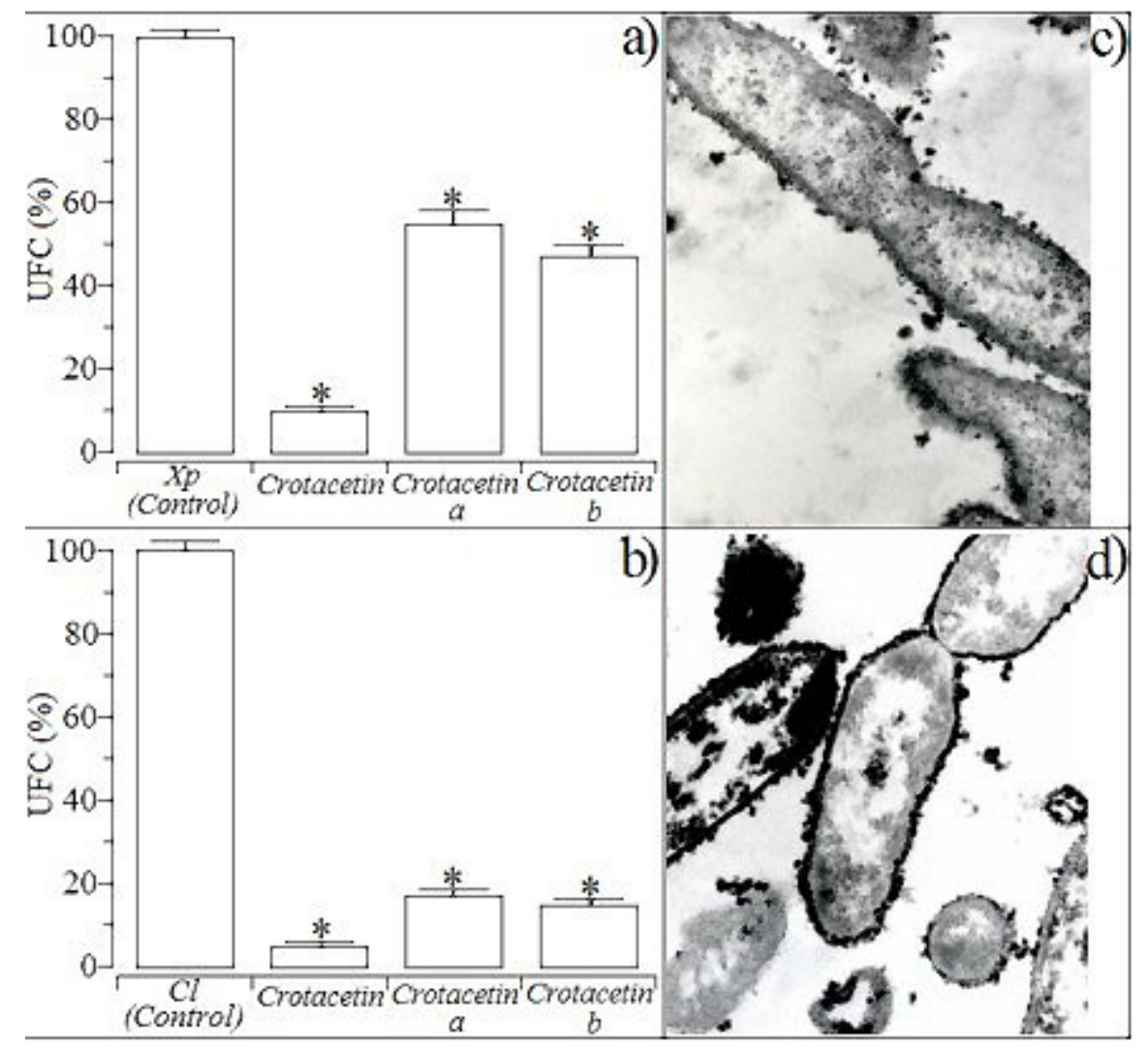

Figure 5: Antimicrobial activity of native crotacetin and isolated $\alpha$ and $\beta$ subunits.

A - Xanthomonas axonopodis pv passiflorae and B - Clavibacter michiganensis michiganensis were incubated with native crotacetin or with isolated $\alpha$ and $\beta$ subunits. The reduction of anti-bacterial activity is compared. C - Transmission electron microscopy of untreated Xanthomonas axonopodis pv passiflorae and D treated with crotacetin. Vacuolization of microbial cells is observed with crotacetintreated bacteria.

\section{DISCUSSION}

Using specific forward primer for 5'-UTR and reverse for 3'-UTR for both subunits of convulxin, subunits $\alpha(\mathrm{CVX} \alpha)$ and $\beta(\mathrm{CVX} \beta)$, we have isolated several cDNA precursor homologs of convulxin (CVX) from Crotalus durissus terrificus venom gland cDNA library. The nucleotide sequence of two of these precursors, precisely of their subunits, $\operatorname{CVX} \alpha$ and $\operatorname{CVX} \beta$ subunit sequences, and the deduced amino acid sequence of СTC $\beta$ are shown in Figure 1. These cDNA sequences present conserved nucleotides starting at - $27 \mathrm{bp}$, from the ATG initiation codon, extending several bases along the precursor. All of the isolated genes, coding for convulxin-like 
subunits, encompass open reading frames (ORFs) of approximately 500 nucleotides (nt) - CVX $\beta, 490 \mathrm{nt}$; CTC $\beta, 513 \mathrm{nt}$; CVX $\alpha, 537 \mathrm{nt}$; ATLs, $522 \mathrm{nt}$. Crotacetin $\beta$ and CVX $\beta$ genes are almost identical (82\% of similarity, 439/537 nt), whereas CVX $\alpha$ and ATLs genes are more related to each other (about 83\%, 409/490 nt). When CTC $\beta$ mRNA is compared with other sequences in the gene databank, more than $86 \%$ identity is found. For example, mucrocetin $\beta$ chain mRNA (AY390534), from Protobhotrops mucrosquamatus, shares $87 \%$ identity (439/537 nt). Hundreds of mRNA sequences of snake venom C-type lectin, from GenBank, share some similarity with crotacetin $\beta$ subunit and with each other.

The high homology between $C$. durissus C-type lectin genes and some other aggregating toxin genes from different snakes points out to their own evolutionary history. These genes seem to have arisen from more than one single event of gene duplication, what probably occurred after the division of Viperidae and Colubridae. The $\alpha$ - and $\beta$-chains of the C-type lectins are restricted to viper and pit viper snakes and therefore compose a monophyletic gene clade (11). However, duplication is not the exclusive event for toxin gene evolution; nucleotide substitution (transversion and transition) and deletion also play some role. Consequently, families of homologous genes and polypeptides are generated with diverse functions or targets. In fact, toxin genes present extremely highly conserved non-coding regions, whereas hyperdiverse coding regions are found $(1,30,33,46)$. In general, the coding region of a given toxin gene lies in exon, which is separated from each other encompassing the leader sequence of the toxin and the 5'-UTR $(6,34,37)$. Thus, the gene organization has influenced not only its own evolution, but also the toxin diversity. For instance, gene organization contributes to accelerated evolution of polypeptides, since gene hypervariation benefits evolutionary advantage $(27,32,45)$.

Comparison between a deduced amino acid sequence of crotacetin $\beta$ subunit and members of snake venom hemorrhagic toxins corroborates a consensual structural characteristic of convulxin-like proteins: the eight conserved residues of cysteine. Six cysteine residues are involved in intra-chain disulfide bridges, linking at 4-15, 32-121 and 98-113 residues, and the other two cysteines are recruited in the formation of the heterodimer, in a head-to-head manner, resulting in the $\alpha_{4} \beta_{4}$ quaternary structure $(20,29)$. To explore the structural conformation adopted by crotacetin $\beta$ subunit and to build a 3-D model of CTC $\beta$, we had utilized amino acid sequences and coordinate 
data from convulxin-like snake venom C-type lectins, whose crystal structures were previously resolved by X-ray diffraction. It is very well known that the two most critical problems in homology modeling are the similarity degrees among target sequences and templates, and evidently the alignment fidelity (42). In the case of crotacetin $\beta$ subunit, its predicted 3-D structural model is practically identical to the experimentally resolved ones.

Crotacetin $\beta$ subunit was initially cloned from Crotalus durissus terrificus venom gland, but latter it was noted that crotacetin is found in the venom of diverse Crotalus durissus subspecies, appearing as a minor fraction peak in chromatograms of the venoms of Crotalus durissus cascavella, Crotalus durissus terrificus and Crotalus durissus collilineatus. In the venom of Crotalus durissus cascavella, the amount of crotacetin is significantly abundant (around $0.8 \%$ of all proteins in the crude venom). The observation that crotacetin is expressed in the venom of several subspecies of South American rattlesnakes, inhabiting distinct geographical locations, confirm the phenomenon of hypervaryability widely seen in the snake venom composition (43, 44). Interestingly, even if snake venom C-type lectins are diverse, they are restricted to the venom of Viperidae, the family of Crotalus durissus species, as mentioned above and studied in detail elsewhere (11). Thus far, crotacetin was isolated and characterized from the venom of $C$. $d$. cascavella.

Based on the fact that СTC $\beta$ subunit seems to belong to the class of convulxin-like proteins, with the consensual motif of C-type lectin domains (CTLDs), including the carbohydrate recognition domain (CRD), two main biological assays with purified crotacetin were conducted: platelet aggregation and antimicrobial test.

Purified crotacetin from Crotalus durissus cascavella appears as two subunits of different sizes (apparent molecular mass of $70 \mathrm{kDa}$ ) and, by gel permeation, a high molecular weight oligomeric form of this protein is evidenced.

Using human platelet rich plasma, it was observed that CTC is capable of aggregating platelets in a dose-dependent manner and, in higher doses, the platelet aggregation is more sustainable than collagen. Actually, platelet aggregation is a common phenomenon of snake venom C-type lectins, usually mediated by glycoprotein receptors on platelet membranes. Kanaji et al. (22) demonstrated that in addition to GPVI, convulxin binds to native human GPIb $\alpha$, exhibiting dual specificity to both platelet receptors. Thus, it remains to be verified what receptor this novel 
member of convulxin-like family is able to bind, that is, would crotacetin be able to interact with and activate platelet via GPVI, GPIb $\alpha$, or other collagen receptor for platelet like GPla-lla ( $\alpha_{2} \beta_{1}$ integrin)? Furthermore, glycoprotein receptors on erythrocyte membranes appear as specific molecular target for convulxin-like snake toxins, as it was demonstrated in a recent work on recombinant BJcuL, a C-type lectin of Bhotrops jararacussu venom (23). Since this is the first report of a new convulxin homolog, it should be also essential from the biochemical point of view to determine not only the strict dependence of crotacetin by calcium ions, as observed for convulxin (49), but also the co-influence of other molecules in the activation and induction of platelet aggregation.

Noteworthy, crotacetin showed a significant antimicrobial activity against two different bacterial strains, Xanthomonas axonopodis pv passiflorae and Clavibacter michiganensis michiganensis. The oligomeric form of crotacetin reduced the overall growth of both bacteria. However, the separation of intact oligomeric protein into their isolated chains abolishes significantly its antimicrobial activity. As seen before, tetrameric form is a typical structure adopted by several snake venom convulxin-like C-type lectins, and this quaternary arrangement seems to be essential for antimicrobial activity. The microscopic effect of crotacetin on Xanthomonas a. pv. passiflorae involved the induction of cytoplasmic vacuolization and membrane rupture. From our point of view, these latter results are of particular relevance, since they concern to antimicrobial activities of a snake venom C-type lectin. The most studied CTLDs-containing proteins with the property of binding to microorganisms are the mannose binding lectins (MBLs) and the lectins receptors located on antigenpresenting cell membranes. MBLs are involved in the mammalian first-line of defense by binding to bacteria, viruses, protozoa, and helminthes, initiating a diverse range of host response (21). In addition, C-type lectin receptors (CLRs) on dendritic cells are type II transmembrane proteins implicated in the pattern recognition of pathogens and in the distinction of self and no-self antigen recognition in mammals (15).

Taken these results together, it is evident that snake venom C-type lectins have their structural domains derived from a common ancestral precursor, which comprises not only a multi-gene family, but also homologous polypeptides possessing conserved Ctype lectin domains with the ability to interact with glycoproteins on blood cell membranes, and with microbial cells as well. 
In this work, we report (a) the cloning of a novel C-type lectin gene from C. durissus terrificus; (b) the isolation and characterization of its gene product, crotacetin $\beta$ subunit, from the venom of three C. durissus subspecies; (c) the predominant presence of crotacetin in the venom of $C$. durissus cascavela; and (d) the prediction of its tridimensional structure. Importantly, we demonstrated that crotacetin induces platelet aggregation and presents antimicrobial activity against both Gram-positive and Gram-negative bacteria.

\section{ACKNOWLEDGEMENTS}

We are thankful to Dr. A. M. Chudzinski-Tavassi, Laboratory of Biochemistry and Biophysics, Butantan Institute, São Paulo, Brazil, for the evaluation of platelet aggregation assays. We are also grateful to Coordenação de Aperfeiçoamento de Pessoal de Nível Superior - CAPES, Conselho Nacional de Desenvolvimento Científico e Tecnológico - CNPq, Fundação de Amparo à Pesquisa do Estado de São Paulo - FAPESP, and Fundação Cearense de Apoio ao Desenvolvimento Científico e Tecnológico - FUNCAP (Brazil). B.S. Cavada and T. Yamane are senior investigators of CNPq (Brazil).

This work was carried out in compliance with the current guidelines governing genetic experimentation in Brazil.

\section{REFERENCES}

1 AFIFIYAN F., ARMUGAM A., TAN CH., GOPALAKRISHNAKONE P., JEYASEELAN K. Postsynaptic alpha-neurotoxin gene of the spitting cobra, Naja naja sputatrix: structure, organization and phylogenetic analysis. Genome Res., 1999, 9, 259-66.

2 ALTSCHUL SF., MADDEN TL., SCHÄFFER AA., ZHANG J., ZHANG Z., MILLER W., LIPMAN DJ. Gapped BLAST and PSI-BLAST: a new generation of protein database search programs. Nucleic Acids Res., 1997, 25, 3389-402.

3 ANDREWS RK., KAMIGUTI AS., BERLANGA O., LEDUC M., THEAKSTON RD., WATSON SP. The use of snake venom toxins as tools to study platelet receptor for collagen and von Willebrand factor. Haemostasis, 2001, 31, 15572. 
4 BATUWANGALA T., LEDUC M., GIBBINS JM., BON C., JONES EY. Structure of the snake-venom toxin convulxin. Acta Crystallogr. D Biol. Crystallogr., 2004, 60, 46-53.

5 BOWIE JU., LUTHY R., EISENBERG D. A method to identify protein sequences that fold into a known three-dimensional structure. Science, 1991, 253, 16470.

6 CHANG L., LIN S., HUANG H., HSIAO M. Genetic organization of alphabungarotoxins from Bungarus multicinctus (Taiwan banded krait): evidence showing that the production of alpha-bungarotoxin isotoxins is not derived from edited mRNAs. Nucleic Acids Res., 1999, 27, 3970-5.

7 CHUDZINSKI-TAVASSI AM., BERMEJ E., ROSENSTEIN RE., FARIA F., SARMIENTO MI., ALBERTO F., SAMPAIO MU., LAZZARI MA. Nitridergic platelet pathway activation by hementerin, a metalloprotease from the leech Haementeria depressa. Biol. Chem., 2003, 384, 1333-9.

8 DALTRY JC., WÜSTER W., THORPE RS. Diet and snake venom evolution. Nature, 1996, 379, 537-40.

9 DRICKAMER K. C-type lectin-like domains. Curr. Opin. Struct. Biol., 1999, 9, 58590.

10 DU XY., CLEMETSON JM., NAVDAEV A., MAGNENAT EM., WELLS TN., CLEMETSON KJ. Ophioluxin, a convulxin-like C-type lectin from Ophiophagus hannah (King cobra) is a powerful platelet activator via glycoprotein VI. J. Biol. Chem., 2002, 277, 35124-32.

11 FRY BG., WÜSTER W. Assembling an arsenal: origin and evolution of the snake venom proteome inferred from phylogenetic analysis of toxin sequences. Mol. Biol. Evol., 2004, 21, 870-83.

12 FUJIMURA Y., TITANI K., USAMI Y., SUZUKI M., OYAMA R., MATSUI T., FUKUI H., SUGIMOTO M., RUGGERI ZM. Isolation and chemical characterization of two structurally and functionally distinct forms of botrocetin, the platelet coagglutinin isolated from the venom of Bothrops jararaca. Biochemistry, 1991, 30, 1957-64.

13 FUKUDA K., MIZUNO H., ATODA H., MORITA T. Crystal structure of flavocetin$A$, a platelet glycoprotein Ib-binding protein, reveals a novel cyclic tetramer of C-type lectin-like heterodimers. Biochemistry, 2000, 39, 1915-23. 
14 FURIHATA K., KATO K., RÁDIS-BAPTISTA G., KUNICKI TJ. Recombinant convulxin induces platelet aggregation. Blood, 2003, 102, 2891.

15 GEIJTENBEEK TBH., VAN VLIET SJ., ENGERING A., HART BA., VAN KOOYK Y. Self-and nonself-recognition by C-type lectins on dendritic cells. Ann. Rev. Immunol. , 2004, 22, 33-54.

16 HAMAKO J., MATSUI T., SUZUKI M., ITO M., MAKITA K., FUJIMURA Y., OZEKI Y., TITANI K. Purification and characterization of bitiscetin, a novel von Willebrand factor modulator protein from Bitis arietans snake venom. Biochem. Biophys. Res. Commun., 1996, 226, 273-9.

17 HARVEY AL. Ed. Natural and synthetic neurotoxins. London: Academic Press, 1993. 360p.

18 HOOFT RW., VRIEND G., SANDER C., ABOLA EE. Errors in protein structures. Nature, 1996, 381, 272.

19 HUANG KF., KO TP., HUNG CC., CHU J., WANG AH., CHIOU SH. Crystal structure of a platelet-agglutinating factor isolated from the venom of Taiwan habu (Trimeresurus mucrosquamatus). Biochem. J., 2004, 378, 399-407.

20 JACK DL., TURNER MW. Anti-microbial activities of mannose-binding lectin. Biochem. Soc. Trans., 2003, 31, 753-7.

21 KANAJI S., KANAJI T., FURIHATA K., KATO K., WARE JL., KUNICKI TJ. Convulxin binds to native, human glycoprotein Ib alpha. J. Biol. Chem., 2003, 278, 39452-60.

22 KASSAB BH., DE CARVALHO DD., OLIVEIRA MA., BAPTISTA GR., PEREIRA GA., NOVELLO JC. Cloning, expression, and structural analysis of recombinant BJcuL, a c-type lectin from the Bothrops jararacussu snake venom. Protein Expr. Purif., 2004, 35, 344-52.

23 LASKOWSKI RA., MACARTHUR MW., MOSS DS., THORNTON JM. PROCHECK: a program to check the stereochemical quality of protein structures. J. Appl. Cryst., 1993, 26, 283-91.

24 LOPEZ-LOZANO JL., DE SOUSA MV., RICART CA., CHAVEZ-OLORTEGUI C., FLORES SANCHEZ E., MUNIZ EG., BUHRNHEIM PF., MORHY L. Ontogenetic variation of metalloproteinases and plasma coagulant activity in venoms of wild Bothrops atrox specimens from Amazonian rain forest. Toxicon, 2002, 40, 997-1006. 
25 MARKLAND FS. Snake venoms and the hemostatic system. Toxicon, 1998, 36, 1749-800.

26 MORRISON GM., SEMPLE CA., KILANOWSKI FM., HILL RE., DORIN JR. Signal sequence conservation and mature peptide divergence within subgroups of the murine beta-defensin gene family. Mol. Biol. Evol., 2003, 20, 460-70.

27 MUKHERJEE AK., MAITY CR. Biochemical composition, lethality and pathophysiology of venom from two cobras - Naja naja and N. kaouthia. Comp. Biochem. Physiol. B. Biochem. Mol. Biol., 2002, 131, 125-32.

28 MURAKAMI MT., ZELA SP., GAVA LM., MICHELAN-DUARTE S., CINTRA AC., ARNI RK. Crystal structure of the platelet activator convulxin, a disulfide-linked alpha $_{4}$ beta $_{4}$ cyclic tetramer from the venom of Crotalus durissus terrificus. Biochem. Biophys. Res. Commun., 2003, 310, 478-82.

29 NAKASHIMA K., NOBUHISA I., DESHIMARU M., NAKAI M., OGAWA T., SHIMOHIGASHI Y., FUKUMAKI Y., HATTORI M., SAKAKI Y., HATTORI S. Accelerated evolution in the protein-coding regions is universal in crotalinae snake venom gland phospholipase $\mathrm{A}_{2}$ isozyme genes. Proc. Natl. Acad. Sci. U.S.A., 1995, 92, 5605-9.

30 NATIONAL CENTER FOR BIOTECHNOLOGY INFORMATION (NCBI). Available from: http://www.ncbi.nlm.nih.gov/

31 OHNO M., CHIJIWA T., ODA-UEDA N., OGAWA T., HATTORI S. Molecular evolution of myotoxic phospholipases A2 from snake venom. Toxicon, 2003, 42, 841-54.

32 OHNO M., MÈNEZ R., OGAWA T., DANSE JM., SHIMOHIGASHI Y., FROMEN C., DUCANCEL F., ZINN-JUSTIN S., LE DU MH., BOULAIN JC., TAMIYA T., MÉNEZ A. Molecular evolution of snake toxins: Is the functional diversity of snake toxins associated with a mechanism of accelerated evolution? Prog. Nucleic Acid Res. Mol. Biol., 1998, 59, 309-64.

33 OLIVERA BM., WALKER C., CARTIER GE., HOOPER D., SANTOS AD., SCHOENFELD R., SHETTY R., WATKINS M., BANDYOPADHYAY P., HILLYARD DR. Specification of cone snails and interspecific hyperdivergency of their venom peptides. Potential evolutionary significance of introns. Ann. N. Y. Acad. Sci., 1999, 870, 223-37. 
34 POLGAR J., CLEMETSON JM., KEHREL BE., WIEDEMANN M., MAGNENAT EM., WELLS TN., CLEMETSON KJ. Platelet activation and signal transduction by convulxin, a C-type lectin from Crotalus durissus terrificus (tropical rattlesnake) venom via the p62/GPVI collagen receptor. J. Biol. Chem., 1997, 272, 13576-83.

35 PRADO-FRANCESCHI J., BRAZIL OV. Convulxin, a new toxin from the venom of the South American rattlesnake Crotalus durissus terrificus. Toxicon, 1981, 19, 875-87.

36 RÁdIS-BAPTISTA G., KUBO T., OGUIURA N., PRIETO DA SILVA AR., HAYASHI MA., OLIVEIRA EB., YAMANE T. Identification of crotasin, a crotamine-related gene of Crotalus durissus terrificus. Toxicon, 2004, 43, 7519.

37 RÁDIS-BAPTISTA G., OGUIURA N., HAYASHI MA., CAMARGO ME., GREGO KF., OLIVEIRA EB., YAMANE T. Nucleotide sequence of crotamine isoform precursors from a single South American rattlesnake (Crotalus durissus terrificus). Toxicon, 1999, 37, 973-84.

38 RAMAKRISHNAN C., RAMACHANDRAN GN. Stereochemical criteria for polypeptide and protein chain conformations. II. Allowed conformations for a pair of peptide units. Biophys. J., 1965, 5, 909-33.

39 RESEARCH COLLABORATORY FOR STRUCTURAL BIOINFORMATICS (RCSB). PROTEIN DATA BANK (PDB). Available from: http://www.rcsb.org/pdb/

40 ROTENBERG D., BAMBERGER ES., KOCHVA E. Studies on ribonucleic acid synthesis in the venom glands of Vipera palaestinae (Ophidia, Reptilia). Biochem. J., 1971, 121, 609-12.

41 SALI A., BLUNDELL TL. Comparative protein modeling by satisfaction of spatial restraints. J. Mol. Biol., 1993, 234, 779-815.

42 SARAVIA P., ROJAS E., ARCE V., GUEVARA C., LOPEZ JC., CHAVES E., VELÁSQUEZ R., ROJAS G., GUTIERREZ JM. Geographic and ontogenic variability in the venom of the neotropical rattlesnake Crotalus durissus: pathophysiological and therapeutic implications. Rev. Biol. Trop., 2002, 50, 337-46. 
43 SHASHIDHARAMURTHY R., JAGADEESHA DK., GIRISH KS., KEMPARAJU K. Variations in biochemical and pharmacological properties of Indian cobra (Naja naja naja) venom due to geographical distribution. Mol. Cell. Biochem., 2002, 229, 93-101.

44 SUMIYAMA K., SAITOU N., UEDA S. Adaptive evolution of the IgA hinge region in primates. Mol. Biol. Evol., 2002, 19, 1093-9.

45 TANI A., OGAWA T., NOSE T., NIKANDROV NN., DESHIMARU M., CHIJIWA T., CHANG CC., FUKUMAKI Y., OHNO M. Characterization, primary structure and molecular evolution of anticoagulant protein from Agkistrodon actus venom. Toxicon, 2002, 40, 803-13.

46 THOMPSON JD., HIGGINS DG., GIBSON TJ. CLUSTAL W. Improving the sensitivity of progressive multiple sequence alignment through sequence weighting, position-specific gap penalties and weight matrix choice. Nucleic Acids Res., 1994, 22, 4673-80.

47 TSAI IH., WANG YM., CHEN YH., TU AT. Geographic variations, cloning, and functional analyses of the venom acidic phospholipases A2 of Crotalus viridis viridis. Arch. Biochem. Biophys., 2003, 411, 289-96.

48 UCHOA HB., JORGE GE., DA SILVEIRA NJ., CÂMERA Jr. JC., CANDURI F., DE AZEVEDO Jr. WF. Parmodel: a web server for automated comparative modeling of proteins. Biochem. Biophys. Res. Commun., 2004, 325, 1481-6.

49 VARGAFTIG BB., PRADO-FRANCESCHI J., CHIGNARD M., LEFORT J., MARLAS G. Activation of guinea-pig platelets induced by convulxin, a substance extracted from the venom of Crotalus durissus cascavella. Eur. J. Pharmacol., 1980, 68, 451-64. 